\title{
Linear Polystyrene-Stabilized PdO Nanoparticle-Catalyzed Mizoroki-Heck Reactions in Water
}

\author{
Atsushi Ohtaka ${ }^{1}{ } *$, Tomohiro Yamaguchi ${ }^{1}$, Takuto Teratani ${ }^{1}$, Osamu Shimomura ${ }^{1}$ and \\ Ryôki Nomura ${ }^{1,2, *}$
}

1 Department of Applied Chemistry, Faculty of Engineering, Osaka Institute of Technology, 5-16-1 Ohmiya, Asahi, Osaka 535-8585, Japan

2 Nanomaterials and Microdevices Research Center, Osaka Institute of Technology, 5-16-1 Ohmiya, Asahi, Osaka 535-8585, Japan

* Authors to whom correspondence should be addressed; E-Mails: otaka@ chem.oit.ac.jp (A.O.); nomura@chem.oit.ac.jp (R.N.); Tel.: +81-6-6954-4729; Fax: +81-6-6957-2135.

Received: 19 September 2011; in revised form: 22 October 2011 / Accepted: 26 October 2011 / Published: 27 October 2011

\begin{abstract}
Linear polystyrene-stabilized PdO nanoparticles (PS-PdONPs) were prepared by thermal decomposition of $\mathrm{Pd}(\mathrm{OAc})_{2}$ in the presence of polystyrene. X-ray diffraction (XRD) and transmission electron microscopy (TEM) indicated the production of $\mathrm{PdO}$ nanoparticles. The loading of palladium was determined by inductively coupled plasmaatomic emission spectroscopy (ICP-AES). PS-PdONPs exhibited high catalytic activity for Mizoroki-Heck reactions under air in water and could be recycled without loss of activity.
\end{abstract}

Keywords: polystyrene; PdO nanoparticles; Mizoroki-Heck reaction; water

\section{Introduction}

The coupling reaction of vinyl or aryl halides with various alkenes in the presence of palladium catalyst is known as the Mizoroki-Heck reaction and represents a powerful tool for building up a new carbon-carbon bonds [1,2]. Recently, attention has focused on the use of palladium nanoparticles (PdNPs) as catalysts in organic synthesis [3-5]. PdNPs supported by a variety of substrates, including poly( $N$-vinylpyrrolidone)- or several organic moieties-grafted silica [6,7], alumina-based oxides [8], mesoporous silica or $\mathrm{NiFe}_{2} \mathrm{O}_{4}[9,10]$, and chitosan [11], have been shown to exhibit high catalytic activity for the Mizoroki-Heck reaction in aprotic, polar solvents such as $N, N$-dimethylformamide and 
dimethylacetamide. However, these solvents are toxic and have high boiling points, which cause difficulties in isolating the products after the reactions. This problem can be minimized by using ionic liquids [12] or performing the reaction under solvent-free conditions [13].

On the other hand, the use of water as a reaction medium for organic synthesis has recently received much attention because water is a readily available, safe, and environmentally benign solvent [14-18]. Several research groups have reported PdNPs-catalyzed Mizoroki-Heck reactions in water [19-25]. For example, Cacchi et al. have developed fluorous silica gel-immobilized perfluoro-tagged PdNPs that can be successfully used and recycled in the Mizoroki-Heck reaction of aryl iodides with allylic alcohols under aerobic phosphine-free conditions [26].

Recently, we found that PdO nanoparticles (PdONPs) are readily stabilized on linear polystyrene, and the resultant polystyrene-stabilized PdONPs (PS-PdONPs) have high catalytic activities for Suzuki and copper-free Sonogashira coupling reactions in water [27-29]. Our continuing interest in the catalytic utility of PS-PdONPs led us to examine herein the Mizoroki-Heck reaction in water.

\section{Results and Discussion}

\subsection{Preparation and Characterization of PS-PdONPs}

Linear polystyrene-stabilized PdO nanoparticles (PS-PdONPs) were prepared according to our previous paper [27]. A mixture of $\mathrm{Pd}(\mathrm{OAc})_{2}$ and linear polystyrene $\left(M_{\mathrm{n}}=6.0 \times 10^{3}\right)$ was added to $1.5 \mathrm{~mol} \cdot \mathrm{L}^{-1}$ aqueous $\mathrm{K}_{2} \mathrm{CO}_{3}$ solution. After the mixture was stirred at $90{ }^{\circ} \mathrm{C}$ for $1 \mathrm{~h}$, the color turned black. An XRD pattern of PS-PdONPs is presented in Figure 1a. In addition to the broad diffraction with $2 \theta$ ranging from $12^{\circ}$ to $28^{\circ}$ ascribed to the polystyrene, other five diffraction peaks assigned to PdO (JCPDS \#41-1107) are observed clearly. Figure 1c shows a TEM image of PS-PdONPs, where a fairly uniform particle size of $2.5 \pm 0.4 \mathrm{~nm}$ is evident. Inductively coupled plasma-atomic emission spectroscopy (ICP-AES) revealed that PS-PdONPs contained an average of $2.5 \mathrm{mmol} \cdot \mathrm{g}^{-1}$ of Pd.

Figure 1. (a) XRD patterns of PS-PdONPs; (b) JCPDS data (\#41-1107) for PdO; (c) TEM micrograph of PS-PdONPs (scale bar $=20 \mathrm{~nm}$ ); (d) Size distribution of PS-PdONPs.

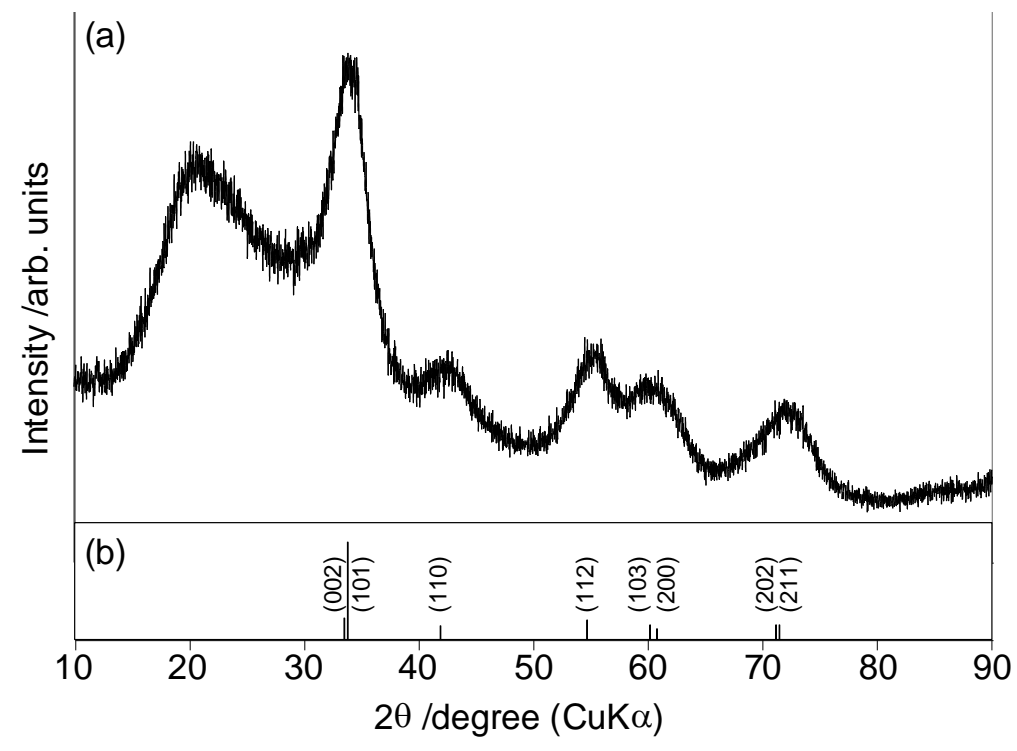


Figure 1. Cont.
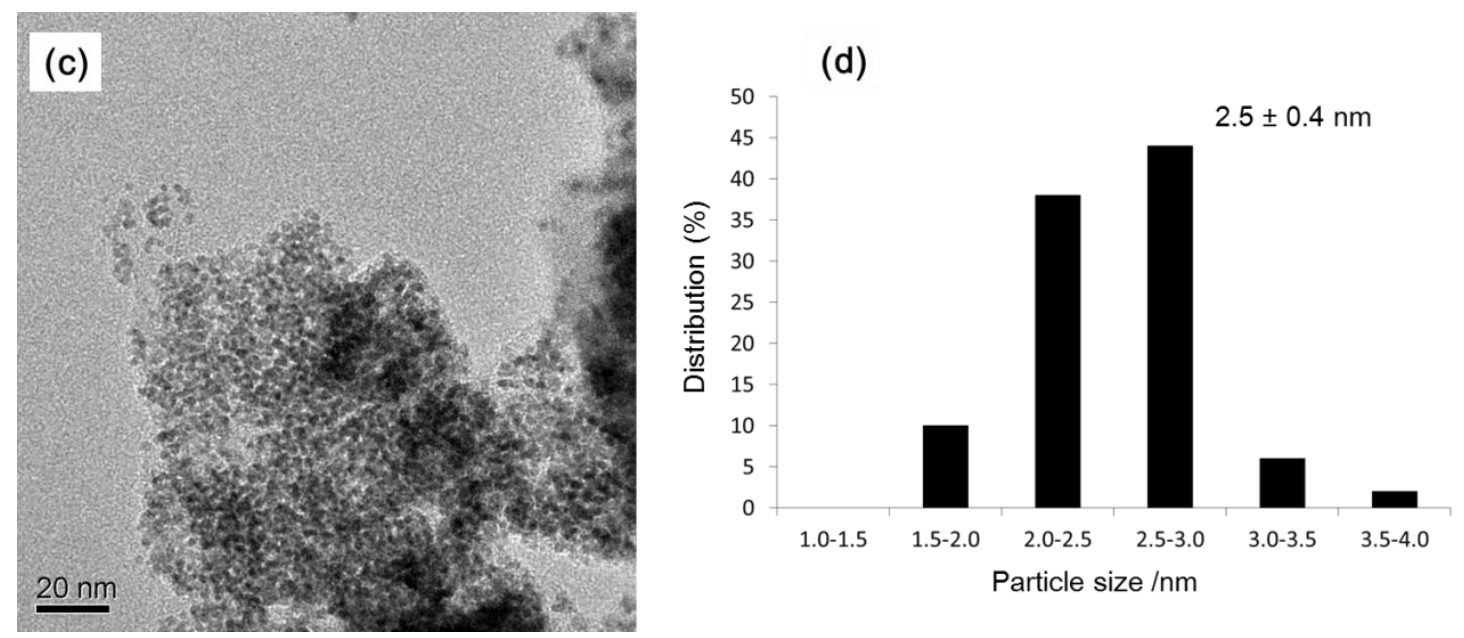

\subsection{Coupling Conditions}

Initially, an optimum base was investigated at $90{ }^{\circ} \mathrm{C}$ in the Mizoroki-Heck reaction of iodobenzene with acrylic acid using PS-PdONPs. As seen in Table 1, the most effective base was potassium hydroxide. Reactions with potassium carbonate, cesium carbonate, and sodium acetate gave trans-cinnamic acid in $27 \%, 19 \%$ and $20 \%$ yields, respectively, probably due to the low basicity. When 1.8-diazabicyclo[5.4.0] undec-7-ene (DBU) and $\mathrm{NEt}_{3}$ was used as a base, the yields of coupling product were $21 \%$ and $96 \%$, respectively. However, the catalyst was not recovered in these cases, suggesting that the strong binding capability of nitrogen was causing palladium leaching. PS-PdNPs, reduced by $\mathrm{NaBH}_{4}$, exhibited slightly lower catalytic activity than PS-PdONPs although reduction of palladium on the surface of the nanoparticles was observed by XRD after treatment of PS-PdONPs with acrylic acid (Figure 2). However, the precise reason for this is as yet unclear, although it suggests that the presence of oxygen is important $[27,30]$. On the contrary, $\mathrm{Pd} / \mathrm{C}$ exhibited low catalytic activity.

Table 1. Effect of base on the Mizoroki-Heck reaction of iodobenzene with acrylic acid using PS-PdONPs in water.

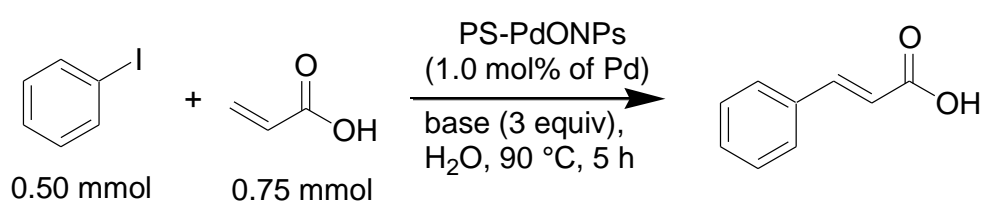

\begin{tabular}{ccc}
\hline Entry & Base & Yield (\%) $^{\mathrm{a}}$ \\
\hline 1 & $\mathrm{KOH}$ & $99(32)^{\mathrm{b}}$ \\
$2^{\mathrm{c}}$ & & $99(16)^{\mathrm{b}}$ \\
$3^{\mathrm{d}}$ & & 44 \\
4 & $\mathrm{~K}_{2} \mathrm{CO}_{3}$ & 27 \\
5 & $\mathrm{Cs}_{2} \mathrm{CO}_{3}$ & 19 \\
6 & $\mathrm{CH}_{3} \mathrm{COONa}$ & 20 \\
7 & $\mathrm{DBU}$ & 21 \\
8 & $\mathrm{NEt}_{3}$ & 96 \\
\hline
\end{tabular}

${ }^{\mathrm{a}}$ NMR yields; ${ }^{\mathrm{b}}$ Reaction time $=1 \mathrm{~h} ;{ }^{\mathrm{c}}$ PS-PdNPs was used as a catalyst;

${ }^{\mathrm{d}} \mathrm{Pd} / \mathrm{C}$ was used as a catalyst. 
Figure 2. (a) XRD patterns of the catalyst after treatment with acrylic acid at $90{ }^{\circ} \mathrm{C}$; (b) JCPDS data (\#87-0641) for Pd (H-loaded).

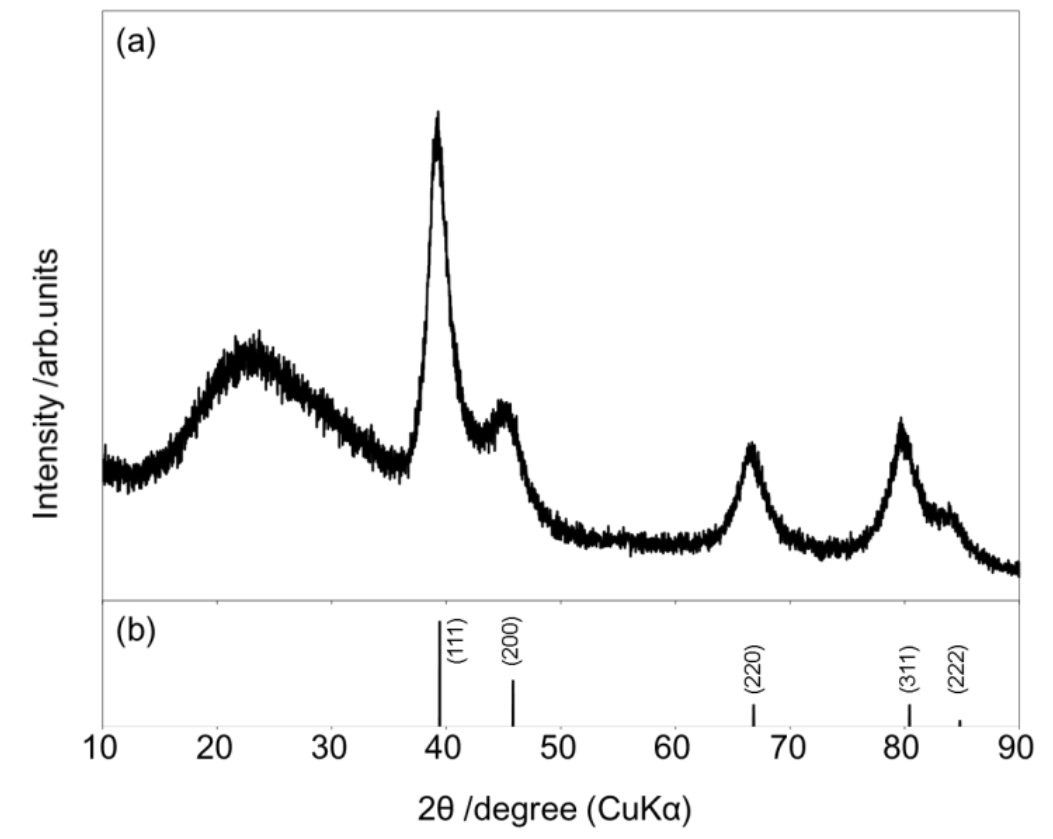

\subsection{Substrate Tolerance}

Employing the optimized reaction conditions, we next examined a variety of substituted aryl iodides having either an electron-releasing or an electron-withdrawing group (Table 2). The reaction of iodobenzene with acrylic acid took place smoothly in water at $90{ }^{\circ} \mathrm{C}$ for $5 \mathrm{~h}$ to give trans-cinnamic acid in $99 \%$ yield (entry 1). The Mizoroki-Heck reaction of 4-iodotoluene and 4-iodoanisole, bearing electron donating groups at the para-position, gave the corresponding cinnamic acids in 99\% and 96\% yields, respectively (entries 2 and 3). Substrates with electron-deficient aromatic rings, i.e., 4-iodoacetophenone and 4-iodobenzotrifluoride, also underwent the Mizoroki-Heck reaction with acrylic acid under similar conditions to afford 4-acetylcinnamic acid and 4-trifluoromethylcinnnamic acid, respectively, both in near quantitative yield (entries 4 and 5). Sterically hindered substrates were also examined. The reaction of 2-iodotoluene and 2-iodophenol with acrylic acid gave the corresponding cinnamic acids in 99\% and 99\% yields, respectively (entries 6 and 7). 1-Iodonaphthalene was also reactive, with the desired product being obtained in $98 \%$ yield (entry 8). It is noteworthy that the formation of 2,6-dimethylcinnamic acid was achieved by the reaction of 2-iodo- $m$-xylene with acrylic acid in 59\% yield (entry 9). The reaction proceeded well with 4-bromoacetophenone, although a longer reaction time was needed (entry 4). However, reactions with styrene and bromobenzene gave low yields (entries 1 and 10).

Table 2. PS-PdONPs-catalyzed Mizoroki-Heck reaction in water.

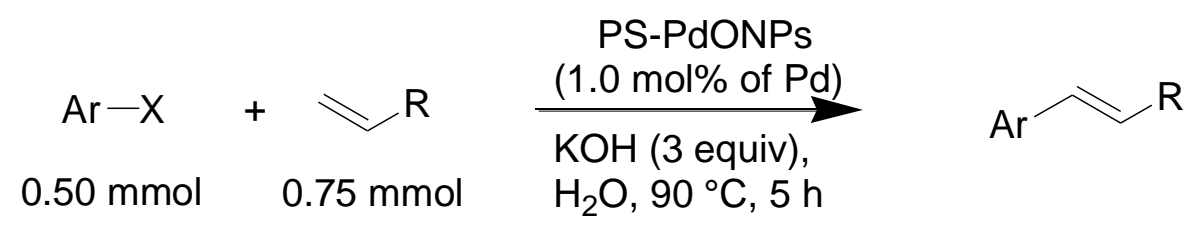


Table 2. Cont.

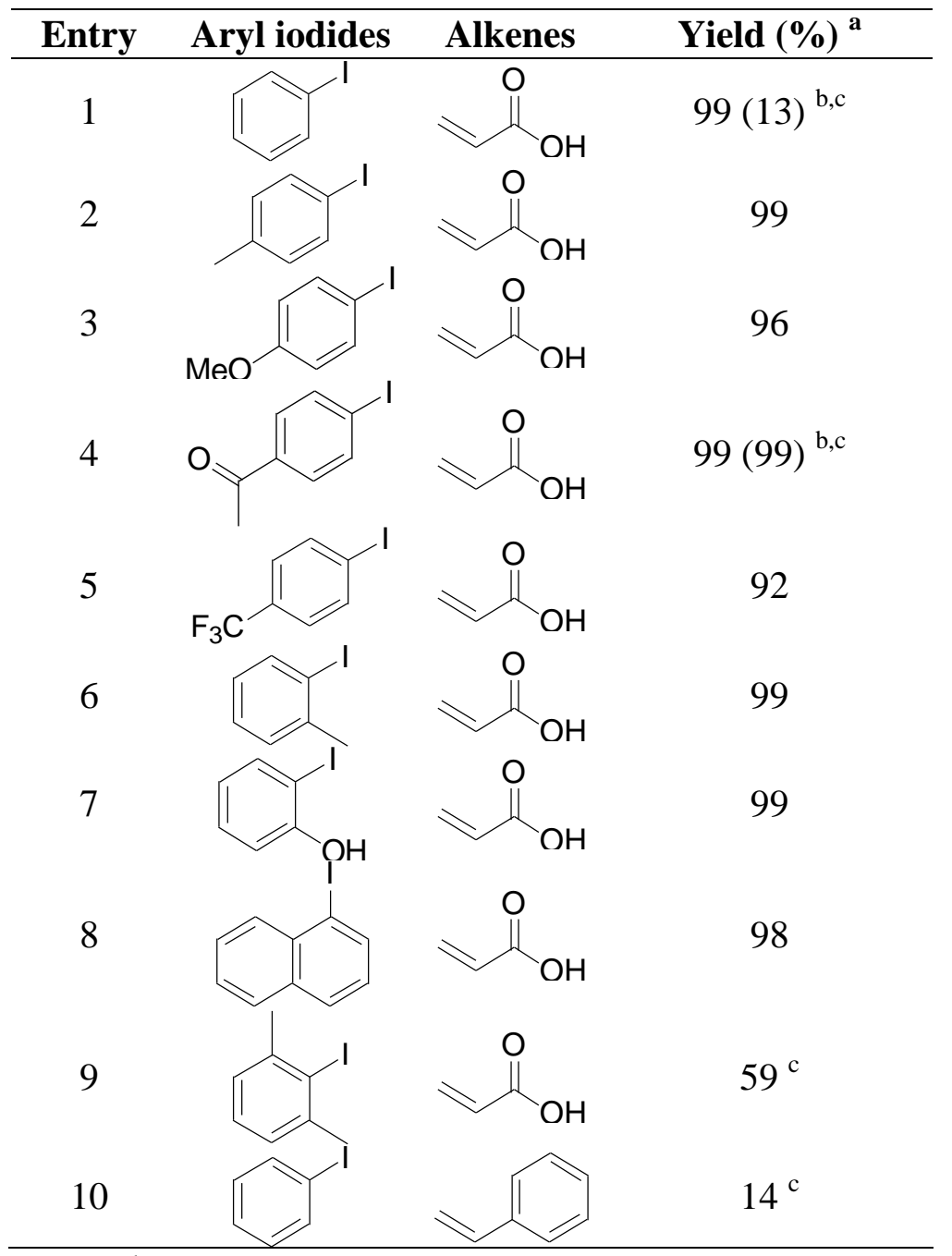

${ }^{\mathrm{a}}$ NMR yields; ${ }^{\mathrm{b}}$ Aryl bromide was used as a substrate; ${ }^{\mathrm{c}}$ Reaction time $=20 \mathrm{~h}$.

\subsection{Recycling Experiments}

Recycling studies were then performed. After the first reaction, which gave a nearly quantitative yield of the product (Table 2, entry 1), the catalyst was recovered and successively subjected to nine more runs of the reaction under the same conditions. As shown in Scheme 1, the yields remained essentially constant for the ten successive runs. After every run, the reaction solutions were analyzed by inductively coupled plasma-atomic emission spectroscopy (ICP-AES) to determine the amount of palladium leached during the reaction. The amount of palladium leaching after every run was $<1.4 \%$. Similar sizes of palladium nanoparticles were observed by TEM after the recycling experiments (after the fifth run, $3.0 \pm 0.6 \mathrm{~nm}$; after the tenth run, $3.0 \pm 0.4 \mathrm{~nm}$, Figure 3 ). When the reaction was interrupted at $16 \%$ conversion and continued after removal of the catalyst (hot filtration test), the residual activity of the reaction mixture was significant (47\% after $20 \mathrm{~h}$ ). This suggests that leached palladium species are, obviously, participating in the catalytic process. However, the data in Table 1 (entries 1 and 2) and the hot filtration test indicate that the soluble forms of palladium are not the only catalytically active species. 
Scheme 1. Recycling experiments.

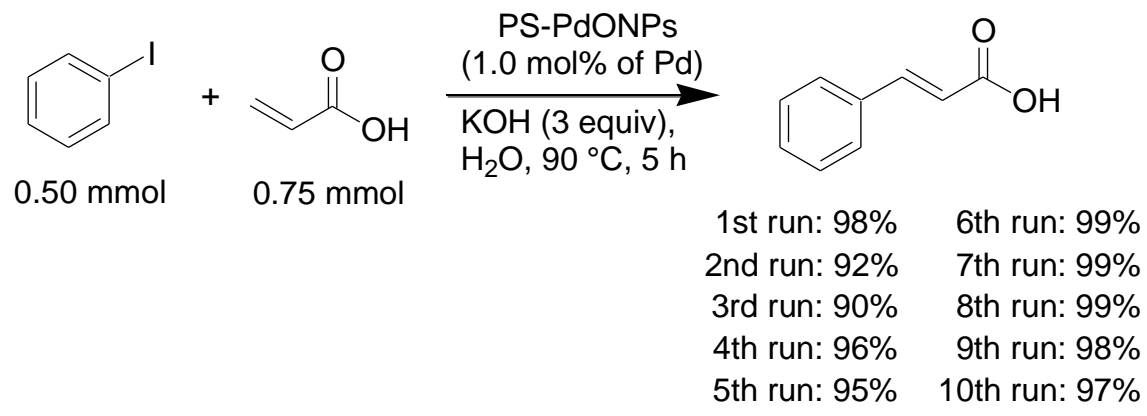

Figure 3. (a) TEM image of the recovered catalyst after the fifth run; (b) Size distribution of the recovered catalyst after the fifth run; (c) TEM image of the recovered catalyst after the tenth run; (d) Size distribution of the recovered catalyst after the tenth run.
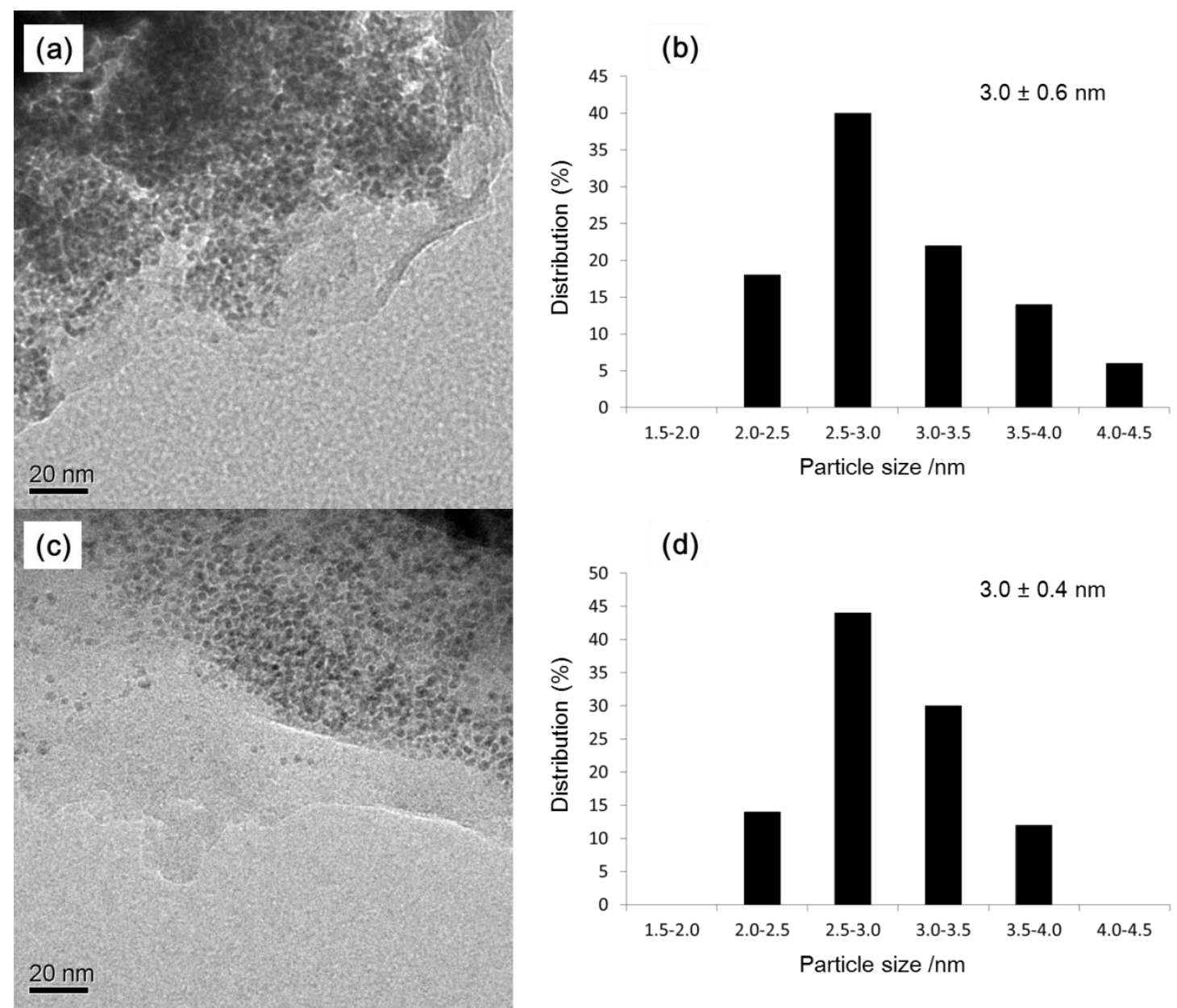

(d)

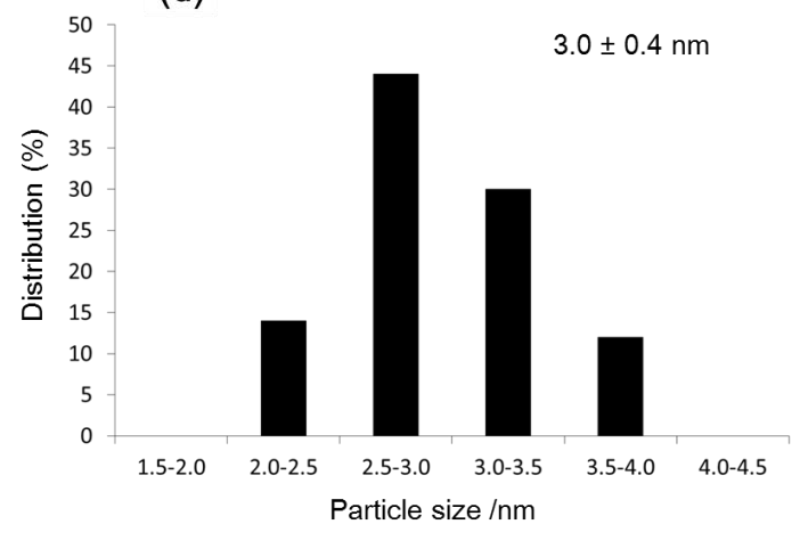

\section{Experimental}

\subsection{General}

${ }^{1} \mathrm{H}-\mathrm{NMR}$ spectra in $\mathrm{CDCl}_{3}$ were recorded with a $300 \mathrm{MHz}$ NMR spectrometer (UNITY 300, Varian, Palo Alto, CA, USA) using tetramethylsilane $(\delta=0)$ as an internal standard. Inductively coupled plasma-atomic emission spectroscopy (ICP-AES) was performed using ICPS-8100 (Shimadzu Co., Kyoto, Japan). Pd nanoparticles were investigated by transmission electron microscopy (TEM) on 
a JEM 2100F transmission electron microscope (JEOL Ltd., Tokyo, Japan). The samples were prepared by placing a drop of the solution on carbon-coated copper grids and allowed to dry in air. Polystyrene of narrow molecular weight distribution standards was purchased from Tosoh Co., Ltd. (Tokyo, Japan). Pd(OAc) $)_{2}$ was obtained from Sigma-Aldrich Co. (St Louis, MI, USA).

\subsection{Preparation of PS-PdONPs}

To a screw-capped vial with a stirring bar was added polystyrene $(9.0 \mathrm{mg}, 85 \mu \mathrm{mol}$ of styrene units), $\mathrm{Pd}(\mathrm{OAc})_{2}(5.5 \mathrm{mg}, 25 \mu \mathrm{mol})$, and $1.5 \mathrm{M}$ aqueous $\mathrm{K}_{2} \mathrm{CO}_{3}$ solution $(3 \mathrm{~mL})$. After stirring at $90{ }^{\circ} \mathrm{C}$ for $1 \mathrm{~h}$, the reaction mixture was filtered with hot water. Subsequently, the polystyrene stabilized $\mathrm{Pd}$ nanoparticles were washed with hot water $(5 \times 1.0 \mathrm{~mL})$ and acetone $(5 \times 1.0 \mathrm{~mL})$.

\subsection{Determination of the Amount of Palladium}

PS-PdONPs (2.9 mg) was placed in a screw-capped vial and then $13 \mathrm{M}$ nitric acid (5 mL) was added. The mixture was heated at $80{ }^{\circ} \mathrm{C}$ to dissolve completely. After cooling to room temperature, the solution was adjusted to $50 \mathrm{~g}$ by water and then the amount of Pd metal was measured by ICP-AES analysis (15.3 ppm). After the catalytic reaction, the aqueous phase was adjusted to $10 \mathrm{~g}$ by nitric acid and then the amount of Pd metal was measured by ICP-AES analysis.

\subsection{Typical Procedures for Mizoroki-Heck Reaction}

To a screw-capped vial with a stirring bar were added iodobenzene $(0.25 \mathrm{mmol})$, acrylic acid (0.25 mmol), PS-PdONPs (1.0 mol\% of Pd), $1.5 \mathrm{M}$ aqueous $\mathrm{KOH}$ solution $(1 \mathrm{~mL})$. After stirring at $90{ }^{\circ} \mathrm{C}$ for $5 \mathrm{~h}$, the reaction mixture was cooled to room temperature by immediately immersing the vial in water $\left(\sim 20^{\circ} \mathrm{C}\right)$. Subsequently, the aqueous phases were removed, and recovered catalyst was washed with water $(5 \times 1.5 \mathrm{~mL})$ and diethyl ether $(5 \times 1.5 \mathrm{~mL})$, which were then added to the aqueous phase. After $6.0 \mathrm{~mol} \cdot \mathrm{L}^{-1} \mathrm{HCl}$ aqueous solution $(0.22 \mathrm{~mL})$ was added to the aqueous phase, the aqueous phase was extracted five times with diethyl ether. The combined organic extracts were dried over $\mathrm{MgSO}_{4}$, concentrated under reduced pressure. The product was analyzed by ${ }^{1} \mathrm{H}-\mathrm{NMR}$. The recovered catalyst was dried in vacuo and successfully reused. Furthermore, the amount of Pd metal in the aqueous phase determined by ICP-AES analysis was $0.1 \mathrm{ppm}$.

\section{Conclusions}

PS-PdONPs was prepared with a simple procedure and demonstrated to be an efficient and reusable catalyst for the Mizoroki-Heck reaction in water. ICP-AES analysis confirmed that palladium leached into the aqueous solution during the reaction. Hot filtration tests indicated the leached palladium species are participating in the catalytic process. In addition, no obvious change in particle size was observed by TEM. Currently, further efforts to extend the application of polystyrene-stabilized metal nanoparticles to other organic reaction in water are under way in our laboratory. 


\section{Acknowledgments}

This work was grateful to the Nanomaterials and Microdevices Research Center (NMRC) of OIT for financial and instrumental supports. We wish to thank Y. Uozumi and G. Hamasaka of Institute for Molecular Science for assistance with TEM measurements. We also thank T. Shinagawa and Y. Kashiwagi of Osaka Municipal Technical Research Institute for ICP-AES and XRD measurements.

\section{Conflict of Interest}

The authors declare no conflict of interest.

\section{References and Notes}

1. Heck, R.F. Palladium-catalyzed reactions of organic halides with olefins. Acc. Chem. Res. 1979, 12, 146-151.

2. Dounay, A.B.; Overman, L.E. The asymmetric intramolecular Heck reaction in natural product total synthesis. Chem. Rev. 2003, 103, 2945-2964.

3. Astruc, D. Palladium nanoparticles as efficient green homogeneous and heterogeneous carboncarbon coupling precatalysts. Inorg. Chem. 2007, 46, 1884-1894.

4. Astruc, D.; Lu, F.; Aranzaes, J.R. Nanoparticles as recyclable catalysts: The frontier between homogeneous and heterogeneouos catalysis. Angew. Chem. Int. Ed. 2005, 44, 7852-7872.

5. Moreno-Mañas, M.; Pleixats, R. Formation of carbon-carbon bonds under catalysis by transitionmetal nanoparticles. Acc. Chem. Res. 2003, 36, 638-643.

6. Tamami, B.; Allahyari, H.; Ghasemi, S.; Farjadian, F. Palladium nanoparticles supported on poly( $N$-vinylpyrrolidone)-grafted silica as new recyclable catalyst for Heck cross-coupling reactions. J. Organomet. Chem. 2011, 696, 594-599.

7. Ungureanu, S.; Deleuze, H.; Babot, O.; Achard, M.-F.; Sanchez, C.; Popa, M.I.; Backov, R. Palladium nanoparticles heterogeneous nucleation within organically grafted silica foams and their use as catalyst supports toward the Suzuki-Miyaura and Mizoroki-Heck coupling reactions. Appl. Catal. A: Gen. 2010, 390, 51-58.

8. Mieczyńska, E.; Gniewek, A.; Pryjomska-Ray, I.; Trzeciak, A.M.; Grabowska, H.; Zawadzki, M. The Heck arylation of mono- and disubstituted olefins catalyzed by palladium supported on alumina-based oxides. Appl. Catal. A: Gen. 2011, 393, 195-205.

9. Wang, P.; Lu, Q.; Li, J. In situ formation of palladium nanoparticles inside the pore channels of ordered mesoporous silica. Catal. Lett. 2009, 131, 444-450.

10. Gao, Z.; Feng, Y.; Cui, F.; Hua, Z.; Zhou, J.; Shi, J. Pd-loaded superparamagnetic mesoporous $\mathrm{NiFe}_{2} \mathrm{O}_{4}$ as a highly active and magnetically separable catalyst for Suzuki and Heck reactions. J. Mol. Catal. A: Chem. 2011, 336, 51-57.

11. Makhubela, B.C.E.; Jardine, A.; Smith, G.S. Pd nanosized particles supported on chitosan and 6-deoxy-6-amino chitosan as recyclable catalysts for Suzuki-Miyaura and Heck cross-coupling reactions. Appl. Catal. A: Gen. 2011, 393, 231-241.

12. Zhang, G.; Zhou, H.; Hu, J.; Liu, M.; Kuang, Y. Pd nanoparticles catalyzed ligand-free Heck reaction in ionic liquid microemulsion. Green Chem. 2009, 11, 1428-1432. 
13. Firouzabadi, H.; Iranpoor, N.; Ghaderi, A.; Ghavami, M.; Hoseini, S.J. Palladium nanoparticles supported on aminopropyl-functionalized clay as efficient catalysts for phosphine-free C-C bond formation via Mizoroki-Heck and Suzuki-Miyaura reactions. Bull. Chem. Soc. Jpn. 2011, 84, 100-109.

14. Lamblin, M.; Nassar-Hardy, L.; Hierso, J.-C.; Fouquet, E.; Felpin, F.-X. Recyclable heterogeneous palladium catalysts in pure water: Sustainable developments in Suzuki, Heck, Sonogashira and Tsuji-Trost reactions. Adv. Synth. Catal. 2010, 352, 33-79.

15. Yan, N.; Xiao, C.; Kou, Y. Transition metal nanoparticle catalysis in green solvents. Coord. Chem. Rev. 2010, 254, 1179-1218.

16. Grieco, P.A. Organic Synthesis in Water; Blackie Academic \& Professional: London, UK, 1998.

17. Leadbeater, N.E. Fast, easy, clean chemistry by using water as a solvent and microwave heating: The Suzuki coupling as an illustration. Chem. Commun. 2005, 2881-2902.

18. Li, C.J. Organic reactions in aqueous media with a focus on carbon-carbon bond formations: A decade update. Chem. Rev. 2005, 105, 3095-3165.

19. Sawoo, S.; Srimani, D.; Dutta, P.; Lahiri, R.; Sarkar, A. Size controlled synthesis of Pd nanoparticles in water and their catalytic application in $\mathrm{C}-\mathrm{C}$ coupling reactions. Tetrahedron 2009, 65, 4367-4374.

20. Senra, J.D.; Malta, L.F.B.; da Costa, M.E.H.M.; Michel, R.C.; Aguiar, L.C.S.; Simas, A.B.C.; Antunes, O.A.C. Hydroxypropyl- $\alpha$-cyclodextrin-capped palladium nanoparticles: Active scaffolds for efficient carbon-carbon bond forming cross-coupling in water. Adv. Synth. Catal. 2009, 351, 2411-2422.

21. Zheng, P.; Zhang, W. Synthesis of efficient and reusable palladium catalyst supported on pH-responsive colloid and its application to Suzuki and Heck reactions in water. J. Catal. 2007, 250, 324-330.

22. Bhattacharya, S.; Srivastava, A.; Sengupta, S. Remarkably facile Heck and Suzuki reactions in water using a simple cationic surfactant and ligand-free palladium catalysts. Tetrahedron Lett. 2005, 46, 3557-3560.

23. Qiao, K.; Sugimura, R.; Bao, Q.; Tomida, D.; Yokoyama, C. An efficient Heck reaction in water catalyzed by palladium nanoparticles immobilized on imidazolium-styrene copolymers. Catal. Commun. 2008, 9, 2470-2474.

24. Wang, Y.; Zhang, J.; Zhang, W.; Zhang, M. Pd-catalyzed C-C cross-coupling reactions within a thermoresponsive and pH-responsive and chelating polymeric hydrogel. J. Org. Chem. 2009, 74, 1923-1931.

25. Ohtaka, A.; Tamaki, Y.; Igawa, Y.; Egami, K.; Shimomura, O.; Nomura, R. Polyion complex stabilized palladium nanoparticles for Suzuki and Heck reaction in water. Tetrahedron 2010, 66, 5642-5646.

26. Boffi, A.; Cacchi, S.; Ceci, P.; Cirilli, R.; Fabrizi, G.; Prastaro, A.; Niembro, S.; Shafir, A.; Vallribera, A. The Heck reaction of allylic alcohols catalyzed by palladium nanoparticles in water: Chemoenzymatic synthesis of $(R)$-(-)-rhododendrol. ChemCatChem 2011, 3, 347-353.

27. Ohtaka, A.; Teratani, T.; Fujii, R.; Ikeshita, K.; Kawashima, T.; Tatsumi, K.; Shimomura, O.; Nomura, R. Linear polystyrene-stabilized palladium nanoparticles catalyzed C-C coupling reaction in water. J. Org. Chem. 2011, 76, 4052-4060. 
28. Teratani, T.; Ohtaka, A.; Kawashima, T.; Shimomura, O.; Nomura, R. Copper-free Sonogashira coupling in water with linear polystyrene-stabilized PdO nanoparticles. Synlett 2010, 2271-2274.

29. Ohtaka, A.; Teratani, T.; Fujii, R.; Ikeshita, K.; Shimomura, O.; Nomura, R. Facile preparation of linear polystyrene-stabilized Pd nanoparticles in water. Chem. Commun. 2009, 7188-7190.

30. Liu, C.; Yang, W. A fast and oxygen-promoted protocol for the ligand-free Suzuki reaction of 2-halogenated pyridines in aqueous media. Chem. Commun. 2009, 6267-6269.

Sample Availability: Samples of the compounds PS-PdONPs and PS-PdNPs are available from the authors.

(C) 2011 by the authors; licensee MDPI, Basel, Switzerland. This article is an open access article distributed under the terms and conditions of the Creative Commons Attribution license (http://creativecommons.org/licenses/by/3.0/). 